\title{
Antisosial atferd hos tidligere ungdomspsykiatriske pasienter
}

\author{
Ellen Kjelsberg \\ Sogn senter for barne- og ungdomspsykiatri, Instituttgruppe for psykiatri, Universitetet i Oslo \\ Korrespondanse: Ellen Kjelsberg, Sogn senter for barne- og ungdomspsykiatri, Postboks 26 Vinderen, 0319 Oslo \\ Telefon: 22028660 Telefax: 22028641 e-post: ellen.kjelsberg@psykiatri.uio.no
}

\begin{abstract}
SAMMENDRAG
Alle pasienter som var innlagt ved Ungdomspsykiatrisk klinikk ved Statens senter for barne- og ungdomspsykiatri i Oslo i perioden 1963-81 ble i 1996 jamført med Strafferegisteret, Rikstrygdeverkets uføreregister og Dødsårsaksregisteret. I alt 52,0\% ble gjenfunnet i Strafferegisteret, 38,5\% var uførepensjonerte og 13,6\% var døde. Denne artikkelen redegjør nærmere for pasientenes kriminelle løpebane. Hos både menn og kvinner hadde atferdsforstyrrelser, rusproblemer og personlighetsforstyrrelser nær sammenheng med senere kriminalitet. Blant de med registrert kriminalitet hadde $55 \%$ av mennene og $18 \%$ av kvinnene begått voldsforbrytelser. Hos begge kjønn var rusproblemer og dårlig impulskontroll forbundet med voldskriminalitet. Menn som hadde foreldre med antisosial atferd eller rusproblemer hadde også økt forekomst av voldelig kriminalitet. Det var klare systematiske ulikheter mellom pasienter som avsluttet sin kriminelle karriere tidlig og pasienter med fortsatt kriminalitet ut over fylte 21 år. Resultatene støtter derfor Moffitts foreslåtte skille mellom kriminalitet isolert til ungdomstiden og kriminalitet som et livslangt atferdsmønster.
\end{abstract}

\section{Kjelsberg E. Antisocial behaviour in former adolescent psychiatric in-patients. Nor J Epidemiol 2002; 12 (3): 215-219.}

\section{ENGLISH SUMMARY}

All patients admitted to the Adolescent Clinic at the National Centre for Child and Adolescent Psychiatry during the years 1963-81 were followed up in 1996 by record linkage to official registers of crime, disability, and death. A total of $52.0 \%$ had entered the criminal registry, $38.5 \%$ were on disability pension, and $13.6 \%$ had died. The present paper focuses on the criminal trajectories of the patient population. Disruptive behaviour disorders, psychoactive substance use disorders, and personality disorders correlated with later registered criminality in both genders. Among those with registered criminality $55 \%$ of the males and $18 \%$ of the females had committed violent crimes. Drug and alcohol problems and poor impulse control predicted later violent criminality in both genders. In addition, having parents with antisocial behaviour and/or psychoactive substance abuse was correlated with violent criminality in males. A distinction between adolescence-limited and life-course persistent antisocial behaviour, as proposed for adolescents in general (Moffitt 1993), was meaningful applied to the study population.

\section{INNLEDNING}

Jo tidligere antisosial atferd begynner, desto alvorligere er ofte prognosen (1-3). Personer med antisosial atferd har en overhyppighet av psykiske lidelser, særlig stoff- og alkoholproblemer (4-8). I diagnosesystemet DSM-IV (9) inngår antisosiale handlinger blant diagnosekriteriene for atferdsforstyrrelse hos barn og unge og antisosial personlighetsforstyrrelse hos voksne. Også psykotiske lidelser synes å ha en overhyppighet av registrert kriminalitet, særlig voldskriminalitet (10-13).

Ved det som tidligere var Statens senter for barneog ungdomspsykiatri (SSBU), nå Sogn senter for barne- og ungdomspsykiatri, i Oslo, er det gjennomført en større etterundersøkelse av tidligere pasienter fra Ungdomspsykiatrisk klinikk (14). I denne artikkelen vil en, med utgangspunkt i publiserte resultater fra undersøkelsen, søke å belyse en del sentrale spørsmål innen utviklingen av antisosial atferd hos tidligere ungdomspsykiatriske pasienter.

\section{MATERiale OG METODE}

Ungdomspsykiatrisk klinikk ved SSBU åpnet i 1963. Undersøkelsen tok for seg alle innleggelser frem til og med 1. halvår 1981. Frem til midt på 80-tallet var klinikken Norges eneste døgninstitusjon for ungdom med psykiske lidelser. Alle fylker søkte ungdommer inn til utredning og behandling ved SSBU. Materialet er således representativt for hele landet. Pasientseleksjonen endret seg ikke vesentlig i perioden 1963-81: Institusjonen prioriterte de til enhver tid vanskeligste pasientene.

I alt var 1276 ungdommer innlagt i perioden. I for- 
bindelse med etterundersøkelsen var det nødvendig å finne frem til den enkeltes personnummer. Hos 84 var det ikke mulig. I alt 53 personer hadde emigrert, og for 44 personers vedkommende var sykehusjournalene svært mangelfulle eller ikke til å oppdrive. Derfor var det kun mulig å følge opp 1095 (86\%) av de 1276.

Undersøkelsen tok utgangspunkt i journalmaterialet fra innleggelsen på SSBU. Alle pasientene ble rediagnostisert etter DSM-IV før en kjente til resultatene av etterundersøkelsen. En inter-rater-undersøkelse ga tilfredsstillende resultat $(\mathrm{kappa}=0,79)$. Ulike typer atferdsforstyrrelser var den hyppigste lidelsen hos både gutter $(57 \%)$ og piker (32\%). Personlighetforstyrrelser var også hyppig hos piker $(21 \%)$. Deretter var psykoser $(9 \%)$, stemningslidelser $(7 \%)$, angstildelser $(6 \%)$ og rene stofflidelser $(6 \%)$ mest vanlig. Komorbiditet var hyppig (51\%), med stoff/alkoholproblemer som den vanligste bidiagnosen (32\%).

I tillegg ble journalene skåret på en stor mengde bakgrunnsvariabler som ble antatt å kunne være korrelert med forløpet. Stort sett var journalene av meget god kvalitet og ga et godt grunnlag for skåringene. Skårer var blind i forhold til forløp.

Ved innleggelsen på SSBU var gjennomsnittsalderen 15,0 år ( $\mathrm{SD}=1,6$; spredning 11-22), ved etterundersøkelsen i 1996 var den 39,5 år ( $\mathrm{SD}=5,5$; spredning 28-51). Gjennomsnitts observasjonstid etter siste innleggelse var 24,5 år ( $\mathrm{SD}=5,6$; spredning 11-33). I alt ble populasjonen fulgt i 25268 pasientår.

Etterundersøkelsen ble gjennomført som en ren registerundersøkelse i 1996. Pasientlisten ble da jamført med Strafferegisteret, Rikstrygdeverkets uføreregister og Dødsårsaksregisteret.

\section{RESULTATER}

\section{Dodelighet og uforetrygding (15)}

Selv om det ikke er hovedfokus for aktuelle artikkel, skal kort nevnes at det ble påvist en markert overdødelighet i pasientpopulasjonen. I alt 149 pasienter $(13,6 \%)$ var døde på oppfølgningstidspunktet, $18 \%$ av alle menn og $8,5 \%$ av alle kvinner. Dødeligheten var om lag 7 ganger den forventede for begge kjønn (16). Det var også en klar overhyppighet av uførepensjonering: $38,5 \%$ av alle pasientene var ved oppfølgningen uførepensjonert (17).

\section{Prevalensen av registrert kriminalitet (15)}

I alt 569 (52\%) av de 1095 pasientene hadde begått registrerte kriminelle handlinger i løpet av oppfølgingsperioden. Knapt $29 \%$ hadde begått sin første kriminelle handling før innleggelsen på SSBU.

Gjennomsnittsalder ved første kriminelle handling var 17,3 år ( $\mathrm{SD}=4,6$; spredning 13-39). 82\% var straffet mer enn en gang. Langt flere menn (63\%) enn kvinner $(39 \%)$ hadde et kriminelt rulleblad $\left(\mathrm{Chi}^{2}=65\right.$; $\mathrm{p}<0,001)$. Menn var oftere innblandet $\mathrm{i}$ vinningsforbrytelser $\left(\mathrm{Chi}^{2}=6,8 ; \mathrm{p}=0,01\right)$ og voldsforbrytelser
$\left(\mathrm{Chi}^{2}=71,2 ; \mathrm{p}<0.001\right)$, men ikke i narkotikaforbrytelser. Blant seksualforbryterne var det bare menn. De fleste forbrytelsene var av alvorlig karakter, og det var en stor grad av overlapp mellom ulike typer forbrytelser. Se Tabell 1.

Tabell 1. Kriminell aktivitet hos de 569 pasientene gjenfunnet i Strafferegisteret i 1996.

\begin{tabular}{lccc}
\hline & $\begin{array}{c}\text { Menn } \\
\mathrm{n}(\%)\end{array}$ & $\begin{array}{c}\text { Kvinner } \\
\mathrm{n}(\%)\end{array}$ & $\begin{array}{c}\text { Totalt } \\
\mathrm{n}(\%)\end{array}$ \\
\hline Vinningsforbrytelser & $330(89)$ & $159(81)$ & $489(86)$ \\
Voldsforbrytelser* & $204(55)$ & $36(18)$ & $240(42)$ \\
Narkotikakriminalitet & $153(41)$ & $87(44)$ & $240(42)$ \\
Seksualforbrytelser & $31(8)$ & $0(0)$ & $31(5)$ \\
Kun forseelser & $21(6)$ & $19(10)$ & $40(7)$ \\
\hline Total & 372 & 197 & 569 \\
\hline
\end{tabular}

* Inkludert 11 drap

\section{Faktorer som predikerer kriminell utvikling (18)}

Ved hjelp av Kaplan-Meyer overlevelsesanalyser og Cox regresjon ønsket vi å finne frem til uavhengige prediktorer for senere registrert kriminell aktivitet. For å kunne benytte slike overlevelsesanalyser var det $\mathrm{i}$ denne delundersøkelsen nødvendig å ta utgangspunkt $\mathrm{i}$ de 932 pasientene som var ustraffet ved innleggelsen på SSBU og analysere i forhold til tidspunkt for senere eventuell innlemming i Strafferegisteret. Resultatene er gjengitt i Tabell 2. Blant de 201 mannlige pasientene som både hadde en høyrisikodiagnose og også hadde forbrutt seg mot avdelingsreglene ved innleggelsen på SSBU, var risikoen for senere kriminelle handlinger meget stor, 78\%, mens den blant de 137 mennene som ikke hadde disse to kriteriene oppfylt, var en klart lavere risiko, 18\%. Blant de 145 kvinnene med både høyrisikodiagnose og stoff/alkoholproblemer var risikoen høy (61\%) for senere kriminalitet, mens de 169 kvinnene som var uten disse to risikofaktorene, hadde en mye lavere risiko ( $8 \%)$.

Tabell 2. Resultater fra Cox regresjonsanalyse. Faktorer identifisert som signifikante og uavhengige prediktorer for registrert kriminalitet og deres relative risiko (RR) for registrert kriminalitet når til stede.

\begin{tabular}{lccc}
\hline Faktor & RR & $\begin{array}{c}95 \% \text { konfi- } \\
\text { densintervall }\end{array}$ & p-verdi \\
\hline Menn & & & \\
$\quad$ Høyrisiko-diagnose * & 2,9 & $2,0-4,2$ & $<0,0001$ \\
$\quad$ Disiplinærproblemer på skolen & 1,7 & $1,2-2,5$ & 0,005 \\
$\quad \begin{array}{l}\text { Regelbrytende atferd under } \\
\quad \text { sykehusoppholdet }\end{array}$ & 1,6 & $1,2-2,2$ & 0,002 \\
$\quad$ Psykisk mishandling i hjemmet & 1,5 & $1,1-2,0$ & 0,01 \\
Kvinner & & & \\
$\quad$ Stoff- og/eller alkoholproblemer & 2,9 & $1,9-4,2$ & $<0,0001$ \\
$\quad$ Høyrisiko-diagnose * & 2,6 & $1,6-4,2$ & 0,0002 \\
\hline
\end{tabular}

* Atferdsforstyrrelse, stoff- eller alkoholproblemer, eller personlighetsforstyrrelse 
Faktorer som korrelerer med voldelig kriminalitet (19)

De 222 (191 menn og 31 kvinner) pasientene som hadde begått voldsforbrytelser ble sammenlignet med de 287 (146 menn og 141 kvinner) som kun hadde begått ikkevoldelige forbrytelser. De som bare hadde begått forseelser ble utelatt fra analysene sammen med en gruppe som bare hadde kommet med trusler og derfor ble antatt å utgjøre en mellomgruppe.

Svært få individer hadde utført bare voldelige kriminelle handlinger (6 av 222). Det var store systematiske forskjeller mellom individer med og uten voldelig kriminalitet. Menn med voldelig kriminalitet hadde signifikant tidligere kriminell debut, de nådde toppen av sin kriminelle karriere senere, og de avsluttet sin kriminelle karriere ved en høyere alder enn de ikkevoldelige. Gruppeforskjellene var mindre markerte blant kvinnene. Ved hjelp av regresjonsanalyse var det mulig å identifisere bakgrunnsvariabler som var sterke og uavhengige korrelater til voldelig kriminell atferd. Resultatene er gjengitt i Tabell 3.

Tabell 3. Resultater fra logistisk regresjonsanalyse. Faktorer som har signifikant og uavhengig korrelasjon med voldelig kriminalitet og deres odds ratio (OR) for voldelig kriminalitet når til stede.

\begin{tabular}{lccc}
\hline Faktor & OR & $\begin{array}{c}95 \% \text { konfi- } \\
\text { densintervall }\end{array}$ & p-verdi \\
\hline Menn & & & \\
$\quad$ Stoff/alkoholproblemer & 2,9 & $1,7-5,0$ & $<0,001$ \\
$\quad$ Foreldre med antisosialitet eller & 2,1 & $1,3-3,5$ & 0,003 \\
$\quad$ stoff/alkoholproblemer & & & \\
$\quad$ Dårlig impulskontroll & 2,0 & $1,2-3,4$ & 0,01 \\
$\quad$ Voldelig atferd under & 1,9 & $1,1-3,2$ & 0,02 \\
$\quad$ sykehusoppholdet & & & \\
Kvinner & & & \\
$\quad$ Stoff/alkoholproblemer & 3,8 & $1,2-11,5$ & 0,02 \\
$\quad$ Dårlig impulskontroll & 2,7 & $1,1-6,4$ & 0,03 \\
\hline
\end{tabular}

\section{Kriminalitet som et ungdomsfenomen i forhold til som et livslangt avvikende handlingsmonster (20)}

Moffitt og medarbeidere (2) skiller mellom individer som begår kriminelle handlinger $i$ en begrenset periode i ungdommen, nærmest som grenseutprøvende normalatferd, i motsetning til de individene som begynner sin antisosiale atferd $i$ barneårene og fortsetter med denne atferden opp i voksen alder. Er disse begrepene tilsvarende fruktbare applisert på en ungdomspsykiatrisk populasjon?

De ungdommene som hadde havnet i Strafferegisteret ble delt inn i undergrupper etter alder for første kriminelle handling. Av 481 tidligere pasienter med kriminell debut før 21 års alder, hadde 130 (27\%) ingen kriminelle handlinger registrert etter 21 års alder. Disse ble ansett å være individer med kriminalitet begrenset til ungdomstiden. I alt $80 \%$ av guttene og $59 \%$ av jentene fortsatte med kriminalitet ut over ungdomsalderen. Det var store systematiske forskjeller mellom de som avsluttet sin kriminelle løpebane og de som fortsatte med kriminell aktivitet ut over 21-årsalderen. Ulike faktorer var forbundet med slik livslang kriminell aktivitet: Intravenøst stoffbruk og det å ikke bli skrevet ut til hjemmet var klare risikofaktorer hos pikene. Hos guttene var atferdsforstyrrelse ved innleggelsen, stoff- og alkoholproblemer og tidligere opphold på spesialskole klare risikofaktorer for fortsettelse av den kriminelle karrieren ut over ungdomstiden.

\section{DISKUSJON}

Den kriminelle belastningen som er påvist for disse tidligere ungdomspsykiatriske pasientene synes å være klart øket $\mathrm{i}$ forhold til normalpopulasjonen. $\AA$ finne gode sammenligningstall har vist seg vanskelig. Norsk kriminalstatistikk opererer med insidens- og ikke prevalenstall, slik denne undersøkelsen gjør. Dessuten bør man ta utgangspunkt i noenlunde samtidige kohorter. Her skal nevnes at en undersøkelse fra Statistisk sentralbyrå fant at 6,7\% av individer født 1955-57 hadde et kriminelt rulleblad ved slutten av sitt 26. år (21). En rapport fra Barnevernets utviklingssenter har beregnet at i 1991 hadde $10,6 \%$ av alle menn mellom 15 og 34 år havnet i Strafferegisteret (22). Hovedkonklusjonen må altså bli at denne gruppen tidligere ungdomspsykiatriske pasienter hadde en klar overhyppighet av registrert kriminalitet i forhold til normalbefolkningen.

Undersøkelsen identifiserte også sterke, kjønnsspesifikke risikofaktorer, både for kriminalitet i hele pasientgruppen og for voldskriminalitet innen gruppen kriminelle. I tillegg har det vist seg at Moffitts taksonomi for antisosial utvikling kan appliseres på en slik gruppe ungdomspsykiatriske pasienter.

Men hvilken overføringsverdi har funnene? Gir de mening i forhold til dagens ungdomspsykiatriske pasientpopulasjon? Sosiale og økonomiske forhold i Norge har endret seg radikalt de siste 30-40 årene: Narkotikaproblemet er et helt annet i dag enn før, det er også ungdomskriminaliteten. Familiestrukturen har endret seg, med øket skilsmissefrekvens og utearbeidende mødre. Ungdommen tilbringer lengre tid på skolebenken. Det er også etter hvert liten uenighet om at det er en økende forekomst av psykiske lidelser hos unge mennesker, noe som er objektivt reflektert i økende forekomst av selvmord hos unge mennesker (23).

Og ikke minst: Er det de samme pasientene som selekteres til innleggelse i ungdomspsykiatriske institusjoner i dag som den gang? Sannsynligvis ikke. Det polikliniske behandlingstilbudet er et helt annet i dag enn det var for 35 år siden. Nå er det bygget ut et nett av barne- og ungdomspsykiatriske poliklinikker over hele landet (24). Hvordan har innholdet i terapitilbudene endret seg? Og med hvilke følger for forløpet?

Alt dette må tas med når man vurderer dagens nytteverdi av resultatene. Alt tilsier at funnene må tolkes med forsiktighet. En viss 'foreldelse' av data er en uavvendelig ulempe ved alle langtidsstudier. I forløpsstudier må vi forholde oss til undersøkelser som tar 
utgangspunkt i tidligere tiders pasienter. Først om flere år kan vi gjennomføre undersøkelser som sier noe om langtidsprognosen for dagens ungdomspsykiatriske pasienter.

Det sier seg selv at en undersøkelse som kun har registerdata som eneste oppfølgningsmål, har begrenset verdi. Det at en pasient har havnet i Strafferegisteret, betyr ikke nødvendigvis at det har gått dårlig med vedkommende. Undersøkelsen tar kun for seg registrert kriminalitet slik den fremkommer i Strafferegisteret. Den offisielt registrerte kriminaliteten utgjør bare en brøkdel av den faktiske kriminaliteten (25). Mange studier tar utgangspunkt i selvrapportert kriminell aktivitet. Men også selvrapportering har sine svakheter. Fordelen med offisielle data er at de er av robust karakter. Norske registre er gjennomgående av god kvalitet (26). Og kanskje er det mindre tendens til skjevrapportering i registerdata (27). Undersøkelser tyder i alle fall på at de aller fleste individer med alvorlig antisosialt avvik før eller siden havner i offisielle strafferegistre $(1,28)$.

En innvending mot denne typen institusjonsmaterialer er at de må antas å ha en høyere grad av komorbiditet enn den generelle befolkning, dette fordi hver lidelse i seg selv uavhengig fører til en øket sjanse for innleggelse (29). Materialet er derfor ikke representativt for ungdomspsykiatriske pasienter generelt.

Undersøkelsen viste at atferdsforstyrrelser, personlighetsforstyrrelser og alkohol- og stoffproblemer var sterke prognostiske faktorer for senere kriminalitet. Det er som forventet, særlig når man tar i betraktning at disse diagnosene ofte stilles på bakgrunn av et antisosialt atferdsmønster. En slik prediksjon kan med andre ord bli en type sirkelbevis: Pasienten får en høyrisiko-diagnose på grunn av tidligere kriminalitet, og denne diagnosen brukes så til å predikere videre kriminalitet. Dette ble i undersøkelsene søkt unngått ved at de som allerede hadde en registrert kriminell karriere ved innleggelsen på SSBU ble ekskludert fra overlevelsesanalysene som ble brukt for å identifisere mulige prediktive faktorer.

Av positive sider ved undersøkelsen kan trekkes frem at materialet er stort, også i internasjonal sammenheng, en stor andel av pasientene er gjenfunnet $i$ registrene, og oppfølgningstiden er lang. Undersøkelsen kan sies å ha et kvasi-prospektivt design fordi de bakgrunnsfaktorene som er undersøkt, ble nedtegnet i ungdommen og ikke på oppfølgningstidspunktet. Derved unngår man faren for at minnet farges av hvordan forløpet har vært.

Pasientene i undersøkelsen var innlagt i en tid da SSBU var landets eneste heldøgns ungdomspsykiatriske avdeling. Opp gjennom årene har ungdom med selvdestruktiv eller alvorlig antisosial atferd og som er til fare for seg selv eller andre, blitt prioritert for innleggelse. Og kanskje har ikke denne 'hårde kjerne' av ungdomspsykiatriske pasienter endret seg spesielt mye over årene.

Den foreliggende etterundersøkelsen har vist at pasienter fra en ungdomspsykiatrisk klinikk hadde dårlig utfall i forhold til kriminalitet, tidlig uføretrygding og død. Det er her viktig å understreke at undersøkelsen ikke kan si noe om eventuell behandlingseffekt. Det er mulig at det ville ha gått enda dårligere uten innleggelse. Men det er å håpe at undersøkelsen vil anspore til videre forskning og øket terapeutisk innsats, og at kunnskapen om risikofaktorer for kriminell utvikling vil kunne brukes til å identifisere undergrupper av ungdomspsykiatriske pasienter med et ekstra stort behov for preventive og kurative tiltak. Målet må være å hindre unge mennesker i å komme inn i en uheldig utvikling med økende antisosial atferd og kriminalitet. Med ovenfor diskuterte forbehold, mener jeg derfor at undersøkelsen har verdi for dagens klinikere, helseplanleggere og de som driver kriminalitetsforebyggende arbeid.

\section{REFERANSER}

1. Farrington DP. The twelfth Jack Tizzard memorial lecture. The development of offending and antisocial behaviour from childhood: key findings from the Cambridge study in delinquent development. $J$ Child Psychol Psychiatry 1994; 36: 929-964.

2. Moffitt TE. Adolescence-limited and life-course persistent antisocial behavior: a developmental taxonomy. Psychol Rev 1993; 100: 674-701.

3. Loeber R, Farrington DP. Young children who commit crime: epidemiology, developmental origins, risk factors, early interventions, and policy implications. Dev Psychopathol 2000; 12: 737-762.

4. Brook JS, Whiteman M, Finch SJ, Cohen P. Young adult drug use and delinquency: childhood antecedents and adolescent mediators. J Am Acad Child Adolesc Psychiatry 1996; 35: 1584-1592.

5. Dawkins MP. Drug use and violent crime among adolescents. Adolescence 1997; 32 (126): 395-405.

6. Farrow JA, French J. The drug abuse-delinquency connection revisited. Adolescence 1986; 21: 951-960.

7. Harrison L, Gfroerer J. The intersection of drug use and criminal behavior: results from the National Household Survey on Drug Abuse. Crime Del 1992; 38: 422-443.

8. Van Kammen WB, Loeber R, Stouthamer-Loeber M. Substance use and its relationship to conduct problems and delinquency in young boys. J Youth Adolesc 1991; 20: 399-413. 
9. American Psychiatric Association. Diagnostic and statistical manual of mental disorders, 4th edn. Washington, DC: American Psychiatric Association, 1994.

10. Tuninger E, Levander S, Bernce R, Johansson G. Criminality and aggression among psychotic in-patients: frequency and clinical correlates. Acta Psychiatr Scand 2001; 103: 294-300.

11. Tiihonen J, Isohanni M, Räsänen P, Koiranen M, Moring J. Specific major mental disorders and criminality: a 26-year prospective study of the 1966 Northern Finland birth cohort. Am J Psychiatry 1997; 154: 840-845.

12. Brennan PA, Mednick SA, Hodgins S. Major mental disorders and criminal violence in a Danish birth cohort. Arch Gen Psychiatry 2000; 57: 494-500.

13. Hodgins S. Mental disorder, intellectual deficiency, and crime. Arch Gen Psychiatry 1992; 49: 476-483.

14. Kjelsberg E. A long-term follow-up of adolescent psychiatric in-patients. University of Oslo, 1999.

15. Kjelsberg E, Dahl AA. High delinquency, disability, and mortality - a register study of former adolescent psychiatric inpatients. Acta Psychiatr Scand 1998; 98: 34-40.

16. Kjelsberg E. Adolescent psychiatric in-patients. A high-risk group for premature death. Br J Psychiatry 2000; 176: 121-125.

17. Kjelsberg E. A long-term follow-up study of adolescent psychiatric in-patients. Part III. Predictors of disability. Acta Psychiatr Scand 1999; 99: 243-246.

18. Kjelsberg E, Dahl AA. A long-term follow-up study of adolescent psychiatric in-patients. Part II. Predictors of delinquency. Acta Psychiatr Scand 1999; 99: 237-242.

19. Kjelsberg E. Pathways to violent and non-violent criminality in an adolescent psychiatric population. Child Psychiatry Hum Dev 2002; 33: 29-41.

20. Kjelsberg E. Adolescence-limited versus life-course-persistent criminal behaviour in adolescent psychiatric inpatients. Eur Child Adolesc Psychiatry 1999; 8: 276-282.

21. Official Statistics of Norway. Criminal statistics survey 1970-1982. Oslo-Kongsvinger: Central Bureau of Statistics, 1984.

22. Falck S. Utlendinger og kriminalitet. Oslo: Barnevernets Utviklingssenter, 1992.

23. Kringlen E. Psykiatriens samtidshistorie. Oslo: Universitetsforlaget, 2001.

24. Apenhet og helhet. Om psykiske lidelser og tjenestetilbudene. Stortingsmelding Nr. 25. Oslo: Sosial- og helsedepartementet, 1997.

25. Finstad L, Høigård C. Kriminologi. Oslo: Pax Forlag, 1997.

26. Mortensen PB, Allebeck P, Munk-Jørgensen P. Population-based registers in psychiatric research. Nord $J$ Psychiatry 1996; 50 (Suppl. 36): 67-72.

27. Elliot D, Ageton S, Huizinga D, Knowles B, Canter R. Prevalence and incidence of delinquent behavior: 1976-80. Boulder, CO: Behavioral Research Institute, 1983.

28. Huizinga D, Elliott DS. Reassessing the reliability and validity of self-report measures. J Quant Criminol 1986; 2: 293-327.

29. Berkson J. Limitations of the application of four fold table analysis to hospital data. Biometry Bull 1946; 2: 47-53. 